\title{
$\mathrm{EG} / \mathrm{AD}$ 모형빙 정도 향상을 위한 콜드룸에서의 생성기법 및 계측기법 연구
}

조성락 ${ }^{\dagger} \cdot$ 정성엽 $\cdot$ 하정석 $\cdot$ 강국진

한국해양과학기술원 해양운송연구부 1

\section{An Experimental Study on Generation and Measurement Method of EG/AD Model Ice at Cold Room for Improvement of Its Properties}

Seong-Rak Cho' ${ }^{1} \cdot$ Seong-Yeob Jeong'· Jung-Seok Ha' ${ }^{1}$ Kuk-Jin Kang ${ }^{1}$

Maritime Transportation Research Division, KIOST, Daejon, Korea'

This is an Open-Access article distributed under the terms of the Creative Commons Attribution Non-Commercial License(http://creativecommons.org/licenses/by-nc/3.0) which permits unrestricted non-commercial use, distribution, and reproduction in any medium, provided the original work is properly cited.

Generation and measurement methods of EG/AD model ice, which is used in KIOST ice model basin are investigated for improvement of its properties. Temperature of seed water, air temperature in the freezing phase and the target air temperature in the tempering phase were changed in the cold room, and the properties of model ice was measured in this conditions. We also verified a conventional measuring method of flexural strength of model ice caused a little measuring error in cold room, so that we suggested a new measuring method that must be used higher supports than double the thickness of the model ice. In this study, we improved the generation and measurement technique of EG/AD model ice, and the developed procedure at cold room can be applied to the KIOST ice model basin.

Keywords : Ice model basin(빙해수조), Model ice(모형빙), Flexural strength(굽힘강도)

\section{1. 서 론}

빙해수조는 빙해역에서의 선박과 구조물 등의 성능을 건조 전 시험하고 평가하기 위한 시설이다. 빙해수조가 선형시험수조 및 해양공학수조와 다른 가장 큰 차이점은 해빙을 모사한 모형빙 (Model ice)을 생성하여 준비하고 정확한 해석을 위한 모형빙의 물리적 특성을 계측해야 한다는 점이다. 또한 목표 빙두께 및 강 도로 준비된 하나의 모형빙판(Ice sheet)은 한번 모형시험을 수행 하고 나면 깨져버리기 때문에 다양한 조건에서 모형시험을 수행 하기 위해서는 여러 모형빙판이 필요하게 된다. 따라서 선박 및 구조물의 성능을 정확히 해석하기 위해서는 여러 모형빙판에서 시험을 수행해야 하며, 준비되는 여러 모형빙판들의 두께 및 강 도 등의 오차를 줄이고 정확하게 물리적인 특성을 계측하는 기술 이 절대적으로 요구된다.

KIOST(Korea Institute of Ocean Science \& Technology) 빙해 수조에서는 캐나다 NRC-IOT(National Research Council-Institute for Ocean Technology) 빙해수조에서 사용하고 있는 EG/AD/S (Ethylene glycol/Aliphatic detergent/Sugar) 모형빙을 개량하여 2009년부터 EG/AD 모형빙을 생성하여 시험하고 있으며, 2013 년 6월 현재 약 90 여판의 모형빙을 생성하였다. KIOST 빙해수
조에서는 현재 모형빙 생성 기법 외에 다양한 선형에 대한 저항/ 자항/조종 시험기법, 모형시험 계측기법 및 다양한 빙상조건에서 의 시험기법 개발로 인하여 모형빙의 정도 향상을 위한 모형빙을 별도로 생성하기가 어렵다. 또한 KIOST 빙해수조에서 한 판의 모 형빙을 생성하려면 많은 비용과 인원이 필요하게 된다. 따라서 본 논문에서는 KIOST 빙해수조 부속의 콜드룸과 축소된 소형수 조(Miniature tank)를 이용하여 EG/AD 모형빙의 생성기법 및 계 측기법 향상을 위하여 본 연구를 수행하였다.

\section{2. 선행 연구}

Timco (1986)는 캐나다 NRC-CHC(Canadian Hydraulics Centre) 에서 기존에 사용하고 있던 요소빙(Carbamide ice)의 파괴 후 잔 류응력 문제를 개선하고자 복합 첨가물을 이용한 새로운 형태의 $\mathrm{EG} / \mathrm{AD} / \mathrm{S}$ 모형빙을 개발하였다. 새로운 모형빙은 1년 정도 지나 면 재료특성이 바뀌는 요소빙에 비해 오랫동안 사용하여도 재료 특성 바뀌지 않으며, 단층형 구조(Single layer)로 요소빙에 비해 하중방향의 영향을 덜 받는 특징을 가진다. 또한 모형빙의 탄성 계수와 굽힘강도의 비를 나타내는 E/of의 값이 1500-2500 정도 로 실해역 해빙의 값에 근사한 장점을 가지고 있다. 국내에서도 
$\mathrm{KIOST}$ 빙해수조 건설 전, $\mathrm{EG} / \mathrm{AD} / \mathrm{S}$ 모형빙의 적용 가능성을 검 토하기 위하여 Kim, et al. (2008)은 콜드룸에서 얼음핵을 분사시 키는 방법을 이용하여 Timco의 결과와 유사한 모형빙의 물리적 특성을 얻었다.

하지만 $\mathrm{EG} / \mathrm{AD} / \mathrm{S}$ 모형빙은 설탕성분으로 인한 박테리아 번식 때문에 수조수를 지속적으로 필터링해 주어야 한다. 이러한 번거 로움을 해결하고, 고가의 설탕 성분 없이 기둥형 구조로 모형빙 을 생성하기 위하여 고온에서 지방성 세제(Aliphatic detergent)를 완전 용해시키는 방법을 이용하여 KIOST 빙해수조에서는 EG/AD 모형빙을 생성하는 절차를 개발하였다 (Cho, et al., 2010a). 그 리고 최근에는 $\mathrm{EG}$ 성분과 $\mathrm{AD}$ 성분의 수조수를 친환경적으로 바꾸 기 위하여 PG(Prophilene glycol)성분과 친환경 세제를 이용한 모 형빙 생성 기법에 대한 초기 실험을 수행하였다 (Kim, 2011).

한편 모형빙의 물리적 특성 계측기법은 각 나라의 빙해수조마 다 고유한 노하우(Knowhow)와 함께 측정되고 있다. 핀란드 AARC(Aker Arctic Research Center)에서는 시험을 수행하는 빙 상조건(Ice conditions)과 그 빙상조건에서 모형빙의 특성을 측정 하는 항목들을 정리하여 발표하였으며 (MARC, 2000), NRC-IOT 빙해수조에서도 빙모형시험 절차서 중 모형빙의 물리적인 특성을 계측하고 계산하는 방법에 대해 자세하게 다루었다 (Jones, 1987). 또한 ITTC(International Towing Tank Conference)에서는 측정기 법 표준화를 위한 가이드를 제정하여 발표하고 있다 (ITTC, 1996, 1999).

KIOST 빙해수조에서도 효율적이고 정확하게 모형빙의 물리적 인 특성을 계측하기 위하여 다양한 계측장비와 측정기법을 개발 하고 있으며 (Lee, et al., 2008; Cho, et al., 2011a, 2011b), 지속적으로 빙모형시험의 정도향상을 위해 연구를 수행하고 있다.

\section{3. 모형빙 생성기법 연구}

$\mathrm{EG} / \mathrm{AD}$ 모형빙의 기본 생성기법은 Fig. 1과 같이 cooling, seeding, freezing 및 tempering의 4 가지 단계를 거쳐 준비하게 된다. $\mathrm{EG} / \mathrm{AD}$ 모형빙의 기본 생성기법은 Fig. 1과 같이 cooling, seeding, freezing 및 tempering의 4 가지 단계를 거쳐 준비하게 된다. Cooling 단계에서는 수조수 표면의 온도를 최대한 떨어뜨 리고, 분사된 얼음핵이 고체로 변하여 유지될 수 있는 대기온도 로 맞추어 주는 과정을 말한다. 통상적으로 대기온도를 $-20{ }^{\circ} \mathrm{C}$ 상태로 하강시키게 되며, 얼음핵이 분사되기 전에 최소 20-30 분 정도 대기온도를 유지시키게 된다. Seeding 단계에서는 cooling 단계에서 생성된 수조수 표면의 불규칙한 얼음을 걷어주 고, 약 $40{ }^{\circ} \mathrm{C}$ 의 청수를 수조 $1-3 \mathrm{~m}$ 상부에서 공기와 함께 분사 시키게 된다. 분사된 미세 크기의 물분자는 바로 고체로 상태변 화하여 천천히 수조수 표면에 안착하게 되며, 그때 수조 내의 대 기온도는 분사된 청수의 영향을 받아 약 $5-6{ }^{\circ} \mathrm{C}$ 정도 상승하게 된다. 다음으로는 실질적으로 모형빙의 두께를 성장시키는 freezing 단계로서, KIOST 빙해수조에서는 통상적으로 $-20{ }^{\circ} \mathrm{C}$ 의 상태로 모형빙을 성장시키고 그 성장률을 측정하고 있다 (Cho, et al., 2010b). 마지막으로는 모형빙의 강도를 맞추기 위하여 대 기온도를 승온시켜주는 tempering 단계로서, 일반적으로 $2{ }^{\circ} \mathrm{C}$ 를 목 표로 대기온도를 설정해 놓고 히터를 자동제어하여 조절하게 된다.

본 연구에서는 $\mathrm{EG} / \mathrm{AD}$ 모형빙의 기본적인 생성기법에서 주요 변수인 분사액 온도, 결빙 대기온도 및 목표 승온 대기온도에 따 른 모형빙의 물리적 특성 변화를 살펴보았다.

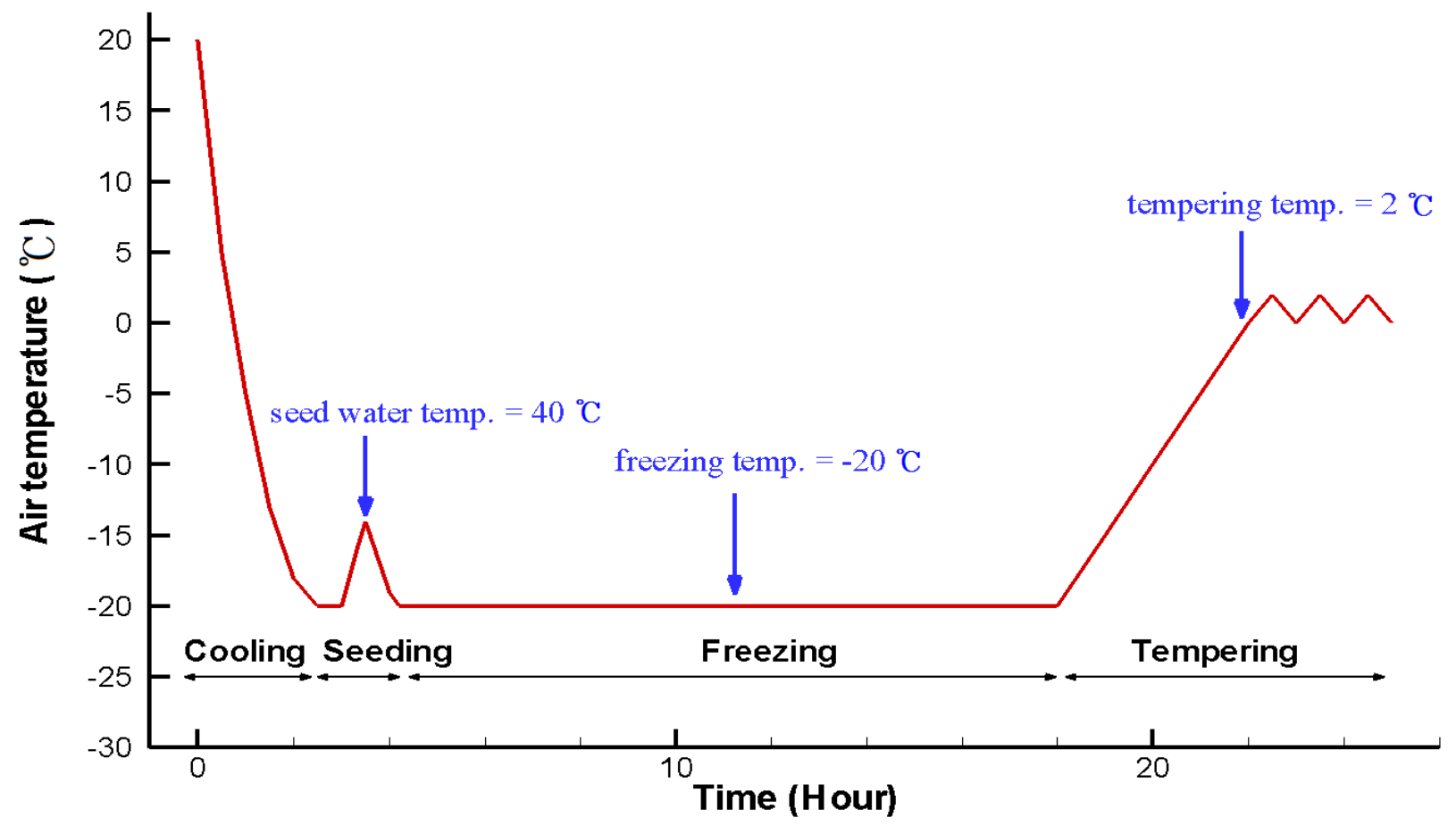

Fig. 1 The air temperature curve during whole generation process of $40 \mathrm{~mm}$ thick model ice 


\section{1 분사액 온도에 따른 모형빙 생성 특성}

모형빙 생성과정에서 청수를 분사하는 seeding 단계는 모형빙 의 물리적/역학적 특성을 결정짓는 매우 중요한 과정이며, 균일 한 모형빙을 생성하는데 반드시 필요한 절차이기도 하다. 캐나다 NRC-IOT 수조의 경우, 30분 이상의 분사시간을 고려하여, 노즐 의 동결을 막기 위하여 약 $40^{\circ} \mathrm{C}$ 의 청수를 분사하고 있으며, KIOST 빙해수조도 비슷한 온도조건에서 얼음핵을 만들어 분사를 진행하고 있다.

본 연구에서는 축소된 수조를 사용하기 때문에 수동의 소형 분 무기를 이용하여 1 분 정도 얼음핵을 분사하였다. 따라서 분사 노 즐의 동결 문제를 고려하지 않고, 분사액(seed water)의 온도에 따른 모형빙의 생성 특성을 조사하였다. KIOST 빙해수조에서와 같이 $40^{\circ} \mathrm{C}$ 의 분사액 온도를 기준으로 점점 분사액 온도를 낮추어 실험을 수행하였으며, 최종적으로 $0^{\circ} \mathrm{C}$ 의 분사액 온도에서도 1 분 이상 분무기가 동결되지 않음을 확인하고 seeding 절차를 수행하 였다.

\section{2 결빙 대기온도 시간에 따른 모형빙 성장률}

수조수 표면에 분사된 얼음핵은 약 $-20^{\circ} \mathrm{C}$ 냉풍의 영향으로 인 해 수조 폭 방향과 깊이 방향으로 동시에 성장을 하다가 근처의 다른 얼음핵과 너비방향으로 성장이 충돌하게 되면 열자속(heat flux) 방향인 깊이 방향으로만 성장을 하게 된다. 얼음핵이 깊이 방향으로 성장하여 기둥형 구조의 얼음이 생성되게 되며, 깊이 방향으로의 성장률은 수조 표면에 공급되는 냉풍의 온도와 세기 에 의해 크게 결정된다.

본 연구에서는 냉풍의 온도와 공급하는 냉풍의 시간을 아래의 관계식 (1)과 같이 $\mathrm{FDH}$ (Freezing Degree Hours)로 정의하여 $\mathrm{FDH}$ 에 따른 모형빙의 성장률을 조사하였다. 냉풍의 온도는 통상 적으로 사용하는 $-20^{\circ} \mathrm{C}$ 를 기준으로 $-18^{\circ} \mathrm{C}$ 와 $-22^{\circ} \mathrm{C}$ 의 대기온도 에서 모형빙의 성장 특성을 실험하였다. 이를 통하여 목표 빙두 께 생성 시, 냉풍의 온도와 결빙시간을 조절하여 모형빙을 생성 할 수 있으며, 모형빙 생성 기법을 발전시킬 수 있었다.

$$
F H D=\left|T_{f}\right| \times t_{f}
$$

여기서, Tf는 freezing 단계에서의 대기결빙온도, $\mathrm{tf}$ 는 결빙시 간을 나타낸다.

\section{3 승온 대기온도에 따른 모형빙 강도 제어기술}

결빙 단계에서 목표 빙두께보다 약간 얇게 생성된 모형빙은 승 온 단계를 거치면서 목표 빙두께에 근접하게 성장하는 동시에 모 형빙의 강도를 떨어뜨려 목표 강도에 도달하기 위한 대기온도 조 절이 필요하게 된다. 통상적으로 KIOST 빙해수조에서는 Fig. 1과
같이 결빙온도에서 $5^{\circ} \mathrm{C} /$ hour 의 변화율을 가지고 대기온도를 올 려주고 있으며, 약 $2^{\circ} \mathrm{C}$ 상태로 대기온도를 유지하면서 모형빙을 지속적으로 tempering 하면서 강도를 맞추고 있다.

본 연구에서는 추가로 $0^{\circ} \mathrm{C}$ 와 $4^{\circ} \mathrm{C}$ 상태로 대기상태를 유지시키면 서 모형빙을 tempering 하여 굽힘강도를 비교하였다. 본 tempering 강도 제어 실험을 위하여 콜드룸 내부에 더미(dummy)의 여러 물 양동이를 추가로 배치(Fig. 2)하여 승온 단계 초기시 $5^{\circ} \mathrm{C} /$ hour 의 변화율을 가지도록 구현하였으며, 승온 단계 중반부에는 콜드룸 출 입문의 개폐 정도를 실시간으로 조절하여 대기온도를 조절하였다.

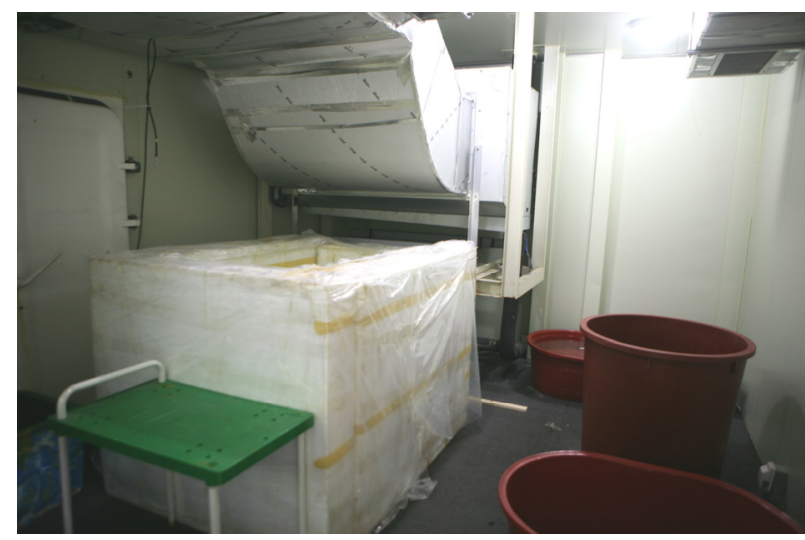

Fig. 2 A miniature tank and some dummy buckets for control of air temperature in cold room

\section{4. 모형빙의 굽힘강도 측정기법 연구}

모형빙의 굽힘강도를 측정하는 방법은 크게 두가지로 나뉜다. 첫째로, 외팔보(cantilever beam)를 만든 후 보의 끝단에 푸쉬풀 게이지로 수직히중을 가한 뒤 보의 최대 파단 히중을 측정하는 방식이다. 보의 형상과 최대 파단 하중을 이용하여 관계식 (2)로 부터 모형빙의 굽힘강도를 계산할 수 있다.

$\sigma_{f}=\frac{6 P L}{B h^{2}}$

여기서, $\mathrm{P}$ 는 최대파단 하중, $\mathrm{L}$ 은 파단된 보의 길이, $\mathrm{B}$ 는 보의 폭, $h$ 는 얼음의 두께를 의미한다.

두 번째 방법은 콜드룸 및 소형수조 등의 좁은 면적의 빙판에 서 사용하는 방법으로, 모형빙을 일정 크기로 잘라내어 단순보를 만든 후 중앙지점에 수직하중을 가한 후 보의 최대 파단 하중을 측정하여 선형탄성보 이론을 통해 굽힘강도를 계산하게 된다.

$\sigma_{f}=\frac{3 P L}{2 B h^{2}}$

본 연구에서는 통상적으로 단순보를 이용한 굽힘강도 계산법 
이 외팔보를 이용한 계산법보다 값이 크게 계측됨을 인지하여 그 원인을 찾고 정확한 굽힘강도 값을 측정하기 위한 방법을 제안하 였다. 즉, 단순보의 양 지지점의 높이가 너무 낮은 경우 숙련된 굽힘강도 계측자라 하더라도 단순보가 파괴된 이후에도 푸쉬풀 게이지에 추가의 하중을 인가하는 현상을 발견하였으며, 단순보 를 이용한 정확한 굽힘강도 측정을 위해서는 충분히 높은 지지대 를 사용해야 한다는 결론을 얻었다. 일반적으로 모형빙의 두께(h) 정도의 지지대 높이에서는 오차값이 많이 발견되었으며, 모형빙 두께의 2 배 정도의 지지대 높이를 사용한 경우 오차가 줄어들었 다. 따라서 콜드룸 등 소형수조 등에서 단순보를 이용하여 모형 빙의 굽힘강도 계측 시, 외팔보를 이용한 굽힘강도 값과 비슷한 값을 얻기 위해서는 지지대의 높이를 $2 h$ 로 충분히 높게하여 최대 파단하중을 계측해야 한다.

한편 모형빙 두께보다 너무 큰 직경의 원형 지지대를 사용할 경우, 선하중(line load)을 줄 수 없기 때문에 지지대의 적당한 크 기와 형태를 잘 선정해야 할 것이다.

\section{5. 실험 결과 및 해석}

균일하고 반복성(repeatibility)이 우수한 모형빙을 생성하기 위 해서는 많은 모형빙 생성 경험과 노하우가 필요하며, 지속적으로 관련 기법을 개발해야 할 것으로 판단된다. 본 연구에서는 모형 빙 생성과정에서 주요한 변수로 작용할 수 있는 분사액 온도, $\mathrm{FDH}$ 및 승온 대기온도의 변화에 따른 모형빙의 생성 특성을 비 교하였으며, 그 실험결과를 다음과 같이 정리하였다.

\section{1 분사액 온도 변화 실험}

Fig. 3은 분사액 온도에 변화를 주어 생성한 3판의 모형빙들의 결정구조를 촬영한 사진이다. KIOST 빙해수조에서 적용하고 있 는 $40^{\circ} \mathrm{C}$ 의 분사액의 경우, 소형수조에서는 상부의 얼음핵 층이 두껍게 형성되고 있으며, 불균일한 특성을 보여 일부는 시편 절 단시 파괴되는 현상을 보이고 있었다. 즉, 분사액이 고체로 상태 변화하지 못하고 액체로 수조수 표면에 떨어지기 때문에 얼음 상 부 표면이 불균일하거나 기둥형 구조로 수조수 표면이 성장하는 데 오랜 시간이 걸리기 때문에 얼음핵 층이 두껍게 형성되었을 것으로 추정된다.

그리고 $30^{\circ} \mathrm{C}$ 와 $0^{\circ} \mathrm{C}$ 의 분사액의 경우, 얇은 얼음핵 층과 일렬 로 배치된 기둥형 구조로 모형빙이 성장했음을 확인할 수 있었으 며, $0^{\circ} \mathrm{C}$ 의 분사액을 사용했을 경우 수조수 표면이 얼음핵으로 덮 혀지는 결과를 얻었다. 따라서 콜드룸에서 모형빙을 생성할 경우 $0^{\circ} \mathrm{C}$ 로 얼음핵을 분사하여 더욱 정도가 우수한 모형빙을 생성하는 기법을 마련하였다. 한편 KIOST 빙해수조에서는 $0^{\circ} \mathrm{C}$ 의 분사액을 사용할 경우, 노즐이 막히는 현상이 발생하기 때문에 노즐이 막 히지 않으면서 얼음핵 층을 잘 형성할 수 있는 낮은 온도의 분사 액 온도에 대한 추가 연구가 필요할 것으로 판단된다.

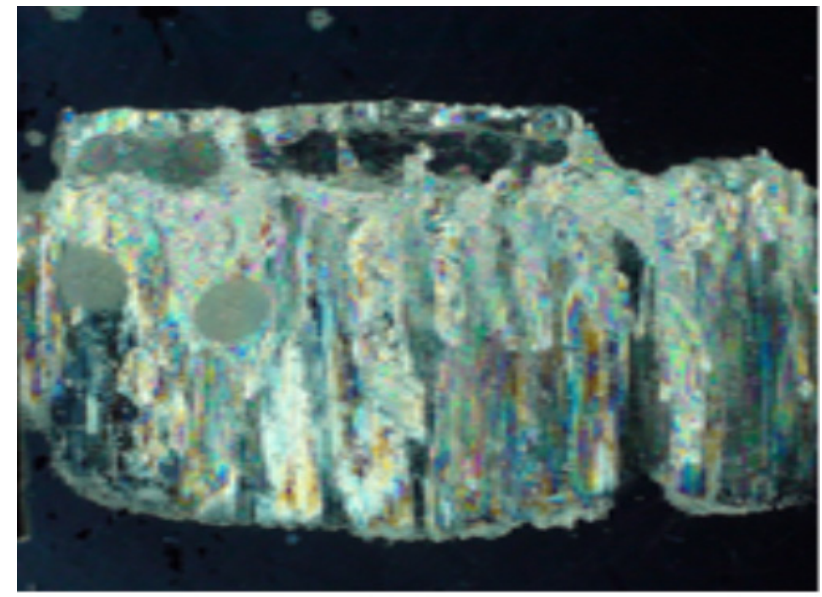

(a) $40^{\circ} \mathrm{C}$ of seed water

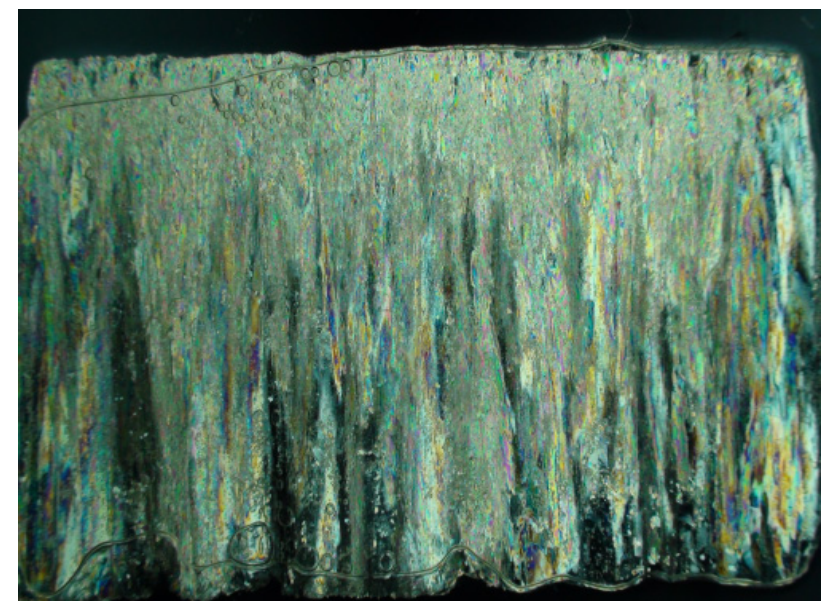

(b) $30^{\circ} \mathrm{C}$ of seed water

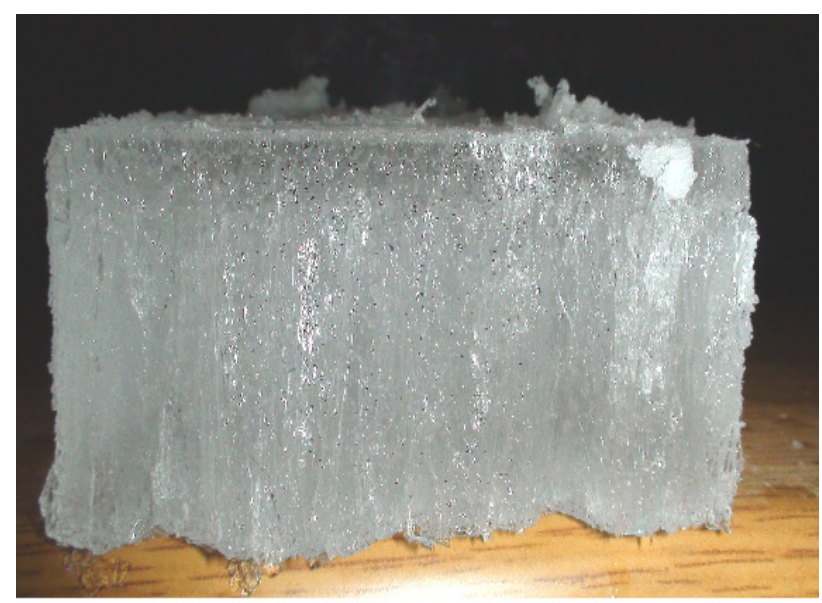

(c) $0^{\circ} \mathrm{C}$ of seed water

Fig. 3 Crystal structure of model ices grown by different temperature of seed water.

\section{$5.2 \mathrm{FDH}$ 에 따른 모형빙 성장률}

Fig. 4 는 $-18^{\circ} \mathrm{C},-20^{\circ} \mathrm{C},-22^{\circ} \mathrm{C}$ 의 결빙 대기온도에서 $\mathrm{FDH}$ 에 따른 얼음의 성장률을 계측하여 나타내었다. Seeding 과정에서 분사액의 온도는 $0^{\circ} \mathrm{C}$ 로 고정하였으며, 소형수조 내의 위치 오 


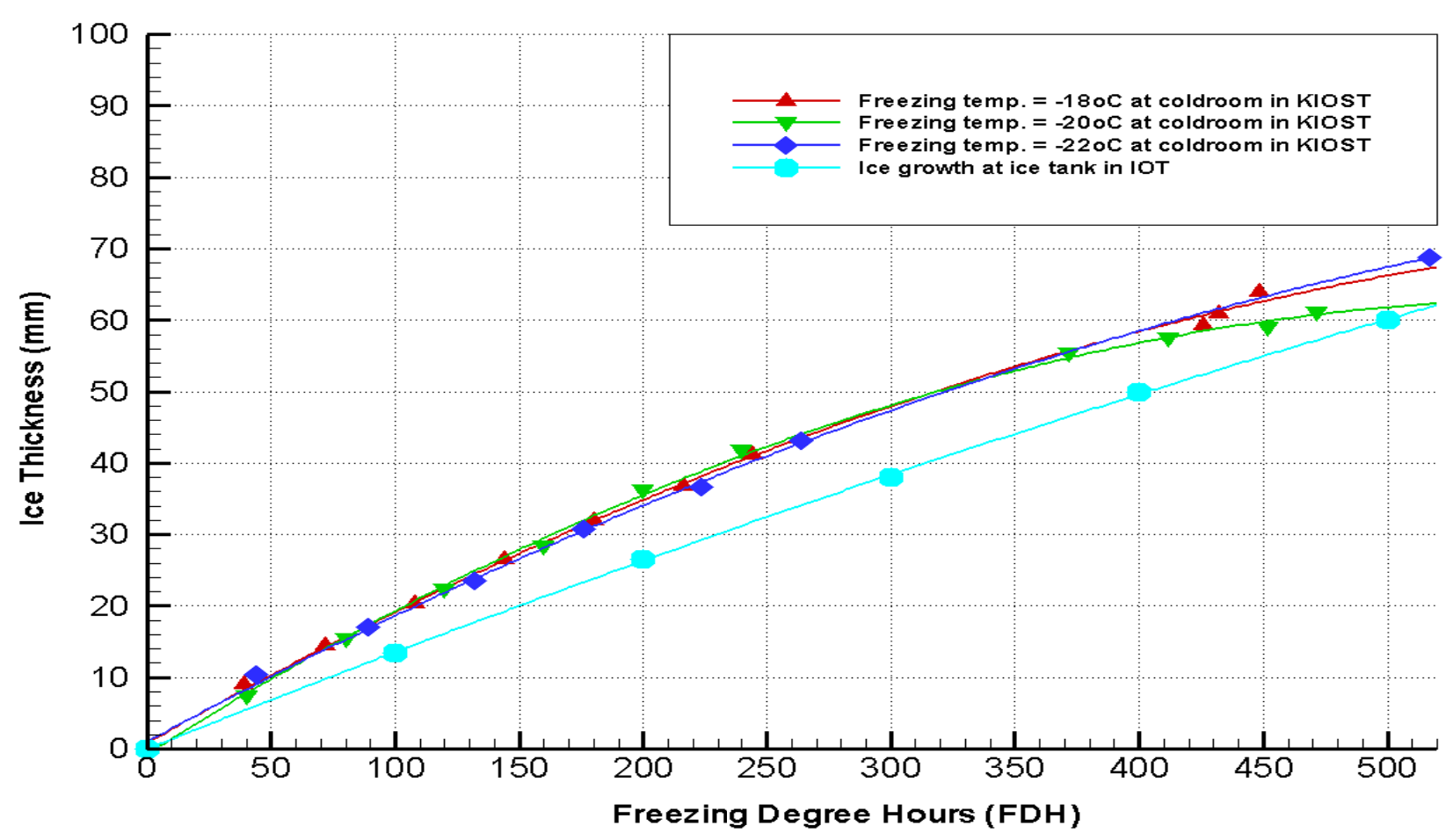

Fig. 4 Comparison of ice growth rate at cold room in KIOST with at ice tank in IOT

차를 줄이기 위하여 계측시간에 따른 계측위치를 동일하게 수행 하였다. 또한 기존에 발표한 캐나다 NRC-IOT 빙해수조의 얼음 성장률 (Jones, 1993)도 함께 비교하여 도시하였다.

KIOST 콜드룸은 내부 크기에 비하여 냉동기 용량이 크기 때 문에 NRC-IOT 빙해수조의 모형빙 성장률보다 크게 성장하고 있 음을 알 수 있다. 또한 결빙이 진행될수록 모형빙이 성장하는 바 닥면까지 열자속 전달률이 떨어지기 때문에 완만하게 성장률이 둔화되고 있음을 확인할 수 있다.

각 결빙 대기온도 $-18^{\circ} \mathrm{C},-20^{\circ} \mathrm{C},-22^{\circ} \mathrm{C}$ 에서 모형빙의 성장 률은 각각 $3.04 \mathrm{~mm} / \mathrm{h}, 3.49 \mathrm{~mm} / \mathrm{h}, 3.61 \mathrm{~mm} / \mathrm{h}$ 였으며, 결빙 대 기온도가 다르더라도 결빙시간을 증가시켜 같은 $\mathrm{FDH}$ 상에서는 거의 유사하게 모형빙이 성장하고 있음을 검증하였다. 따라서 KIOST 빙해수조에서 목표 빙두께를 맞추기 위한 각 결빙온도 별 냉동기 가동 시간을 추정할 수 있게 되며 이를 통하여 효율적인 냉동기 운영과 빙모형시험의 일정을 쉽게 조절할 수 있을 것으로 판단된다.

\section{3 승온 대기온도에 따른 모형빙 강도}

Fig. 5는 승온 대기온도에 따른 모형빙의 굽힘강도 계측결과를 도시하였다. Seeding 단계에서 분사액의 온도는 $0^{\circ} \mathrm{C}$ 로 고정하였 으며, $-20^{\circ} \mathrm{C}$ 의 결빙 대기온도로 11 시간 동안 모형빙을 생성하였 으며, 굽힘강도는 소형수조 중앙부에서 승온 과정이 경과하면서 매 측정시간에 2 개의 시편을 계측하여 평균값을 나타낸 것이다. 또한 $4^{\circ} \mathrm{C}$ 로 대기온도를 승온할 경우 15 시간의 경과 시의 굽힘강 도가 매우 낮게 계측될 것으로 추정하고 경과 9 시간에 추
가로 굽힘강도를 계측하였다. 굽힘강도 추세선은 다항식 2차를 선택하였으며, $4^{\circ} \mathrm{C}$ 의 승온 결과는 데이터 부족으로 13 시간 경과 이후 굽힘강도가 올라가는 것으로 오추정되고 있다.

승온 대기온도가 $0^{\circ} \mathrm{C}$ 에서 $4^{\circ} \mathrm{C}$ 로 상승함에 따라 시간에 따른 굽힘강도 하강률이 약간 커져 굽힘강도가 약간 낮게 계측되고 있 음을 확인하였다. 승온 대기온도를 높여 모형빙의 굽힘강도를 빨 리 낮추게 되면, 빙모형시험을 위한 대기시간을 줄일 수 있게 되 며, 원활하게 모형시험 일정을 조절할 수 있는 장점을 가지게 될 것이다.

\section{6. 결 론}

본 논문에서는 $\mathrm{EG} / \mathrm{AD}$ 모형빙의 생성 정도를 향상하기 위한 생성기법 및 계측기법에 대한 실험적인 연구 결과를 정리하였다. $\mathrm{EG} / \mathrm{AD}$ 모형빙을 생성하는 절차 중, 분사액 온도에 따라 모형빙 상부층의 두께 및 균일도가 차이가 남을 확인하였으며, 분사액 온도가 낮을수록 모형빙 상부의 분시층(seeding layer)이 얇고 균 일하게 성장함을 알 수 있었다. 추후 KIOST 빙해수조에서 적용하 기 위한 최적의 분사액 온도에 대한 연구가 필요할 것으로 사료 된다. 또한 결빙 대기온도와 결빙 시간을 연계하여 FDH에 따른 모형빙의 성장률을 조사하였으며, 이는 대형빙수조에서 모형빙 생성 일정을 준비하는데 좋은 자료가 될 것으로 판단된다. 그리 고 승온 대기온도에 따른 모형빙의 굽힘강도 변화추이를 통해 모 형빙의 굽힘강도를 제어할 수 있음을 알 수 있었다.

한편 모형빙의 물리적 특성 중 큰 비중을 차지하는 굽힘강도 


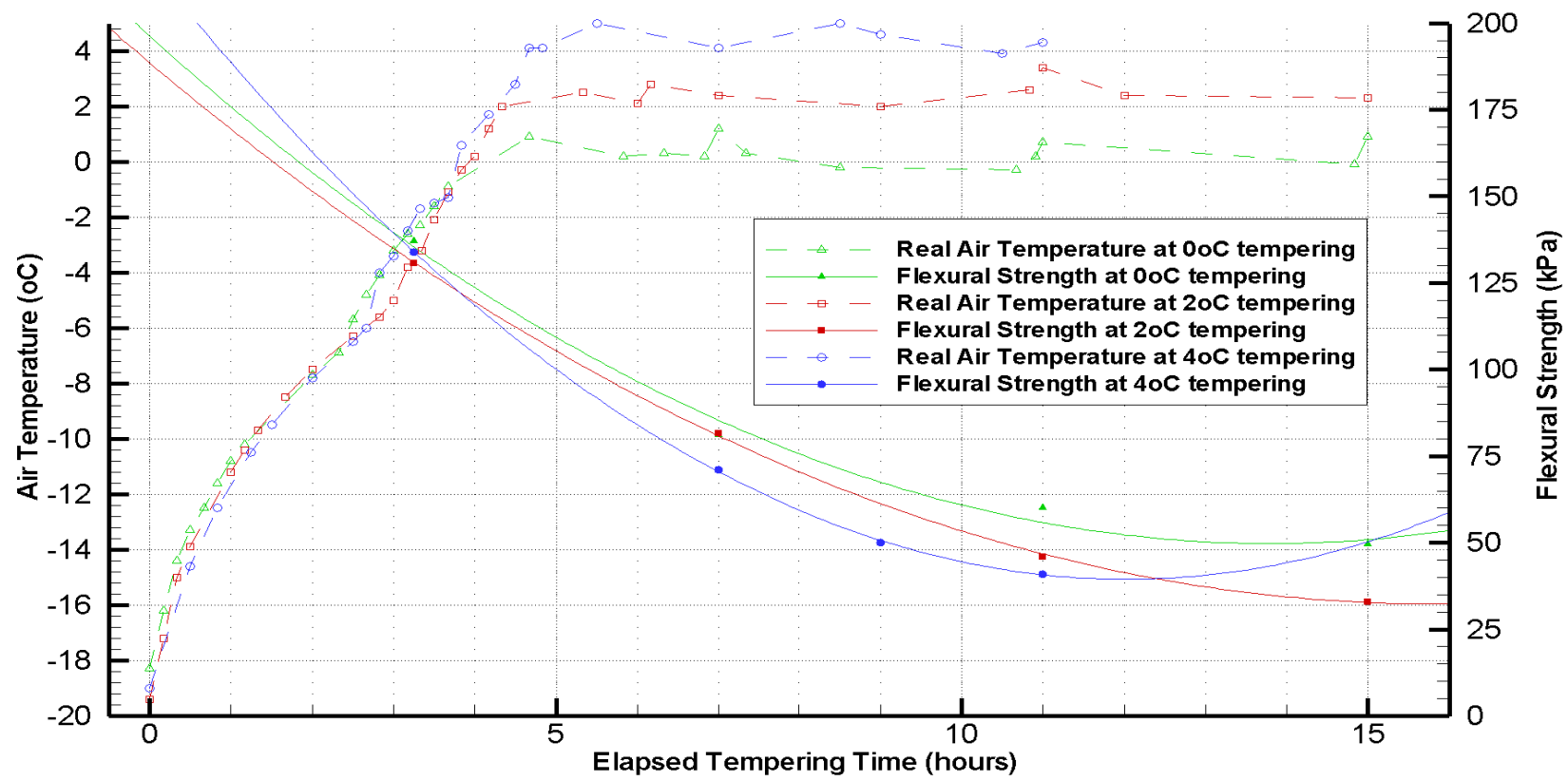

Fig. 5 Measured flexural strength curve of model ice vs. tempering time and some different air temperatures in tempering

측정기법의 문제점을 인지하여, 소형수조 등의 좁은 면적의 모형 빙에서 주로 사용하는 단순보 시험 계측법의 정도향상을 위한 기 법을 개발하였다. 즉, 통상적으로 모형빙 두께 정도의 지지대를 사용하여 단순보 시험을 수행하였으나, 모형빙의 두께보다 충분 히 높은 지지대를 사용해야 계측 오차를 줄일 수 있음을 확인하 였다.

본 연구를 통해 모형빙 생성기법 및 계측기법은 앞으로도 지속 적으로 개발하여 정도를 높여야 함을 다시 한번 알 수 있었으며, 이를 통하여 빙모형시험의 해석정도를 향상시킬 수 있을 것으로 기대된다.

\section{후기}

본 연구는 한국해양과학기술원 주요과제인 "빙해수조의 모형 빙 생성 및 강도 제어 기술 고도화(PES156D)" 및 "빙해수조 모 형빙의 두께분포 계측장비와 기술 개발을 위한 기획연구 (PES1680)"의 지원으로 수행되었으며, 연구비 지원에 감사드립 니다.

\section{References}

Cho, S.R. Lee, C.J. \& Jeong, S.Y., 2010a. An efficient EG/AD model ice for the MOERI ice tank. Proceedings of International Symposium Offshore and Polar Engineering Conference, Beijing China, 20-25 June 2010, pp.1183-1187.
Cho, S.R. Lee, C.J. \& Jeong, S.Y., 2010b. A Study on the Initial Model Ice Generation and Ice Resistance Tests. Journal of Ships \& Ocean Engineering, 49, pp.1-9.

Cho, S.R. Chun, E.J. Yoo, C.S. Jeong, S.Y. \& Lee, C.J., 2011a. The Measuring Methodology of Friction Coefficient between Ice and Ship Hull. Journal of the Society of Naval Architects of Korea, 48(4), pp.363-367.

Cho, S.R. Yoo, C.S. \& Jeong, S.Y., 2011b. Development of Model Test Methodology of Pack Ice in Square Type Ice Tank. Journal of the Society of Naval Architects of Korea, 48(5), pp.390-395.

International Towing Tank Conference(ITTC), 1996. Final Report and Recommendations to the 21st ITTC. Performance in Ice-Covered Waters Committee of the 21st ITTC. ITTC

International Towing Tank Conference(ITTC), 1999. Final Report and Recommendations to the 22nd ITTC. Specialist Committee of the 22nd ITTC.ITTC Jones, S., 1987. Ice Tank Test Procedure at the Institute for Marine Dynamics. Report No. LM-AVR-20, National Research Council of Canada.

Kim, J.H. Choi, K. Jeong, S.Y. Seo, Y.K. Cho, S.R. \& Lee, C.J., 2008. An Experimental Study for the Mechanical Properties of Model Ice Grown in a Cold Room. Journal of the Korean Society of Ocean Engineers, 22(3), pp.64-70. 
Kim, J.H., 2011. A Study on the Material Properties of Compound Model Ice for Utilization in the Ice Model Basin. Ph.D., Busan: Korea Maritime University, Korea.

Lee, C.J. Cho, S.R. Lau, M. \& Wang, J.Y., 2008. A Study on Improvement of Ice Model Test Procedure. Journal of the Society of Naval Architects of Korea, 45(5), 562-568.

MARC, 2000. Standard Ship Model Tests, Ice Conditions and Analysis Methods at Masa-Yards Arctic Research Center. MARC Report D-114. MARC
Timco, G.W., 1986. EG/AD/S : A New Type of Model Ice for Refrigerated Towing Tanks. Cold Regions Science and Technology, 12, pp.175-195.
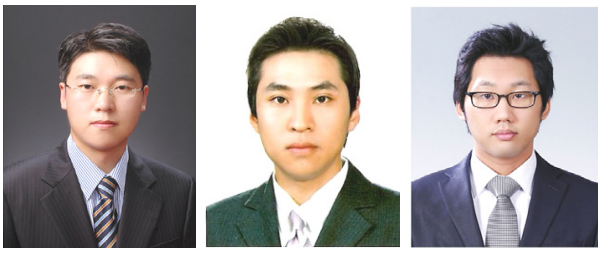

하 정 석

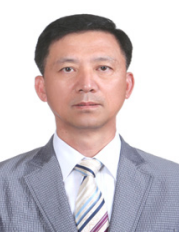

강 국 진 